И. Ф. Беленичев, П. Г. Бак, А. В. Абрамов, Л. И. Кучеренко, Н. В. Бухтиярова, В. П. Рыженко

\title{
Анализ ЭКГ при моделировании хронической сердечной недостаточности у крыс и курсовом введении нового потенциального препарата «Гипертрил»
}

\author{
Запорожский государственный медицинский университет
}

Ключевые слова: хроническая сердечная недостаточность, 4-амино-1,2,4-триазолы, Гипертрил, $\beta$-адреноблокатор, метопролол, кардиопротекция

Хроническая сердечная недостаточность $(\mathrm{XCH})$ - одна из ключевых с клинической и экономической точки зрения проблем для систем здравоохранения большинства развитых стран мира, которую отличает широкая распространенность и неблагоприятный прогноз [1]. Общая смертность при ХСН в зависимости от тяжести заболевания варьирует в пределах от 15 до 50 \%, причем ежегодная смертность больных III и IV функционального класса (ФК) достигает $40 \%$ и свыше $60 \%$ соответственно, а показатели внезапной смертности составляют $50 \%$ и более от общей [2]. Из лекарственных средств (ЛС) с доказанной в отношении ХCH эффективностью наиболее благоприятным образом зарекомендовали себя $\beta$-адреноблокаторы, которые способны улучшать показатели выживаемости и сроков госпитализации больных; эффективно повышать фракцию выброса, уменьшать массу левого желудочка сердца, причем ведущими компонентами данного эффекта этих препаратов являются их кардиопротекторные свойства. Однако молекулярно-клеточные механизмы влияния $\beta$-адреноблокаторов на эти процессы

(C) Колектив авторів, 2021 до конца не выявлены. Кроме того, наличие побочных реакций у $\beta$-адреноблокаторов ограничивает их широкое применение в клинике [3]. В этом ключе разработка новых препаратов с селективным $\beta_{1}$-блокирующим действием и определение выбора разных форм этих препаратов в комплексной терапии ХCH представляет научный интерес. На кафедрах фармацевтической химии и фармакологии Запорожского государственного медицинского института, а затем в НПО «Фарматрон» в результате многолетнего изучения кардиопротекторной, противоишемической, антиоксидантной и фибринолитической активности в ряду производных 4-амино-1,2,4-триазола было выделено соединение (бромид 1-( $\beta$-фенилэтил)-4-амино- $1,2,4$ триазолия), получившее название «Гипертрил», проявляющее $\beta_{1}$-блокирующее, вазодилатационное, антигипертензивное, антиоксидантное, противоишемическое, антиагрегантное и фибринолитическое действие [4-6]. Установлено, что Гипертрил улучшает показатели кардиогемодинамики в условиях острой ишемии миокарда снижает преднагрузку на сердце за счет уменьшения частоты сердечных сокращений (ЧСС) и увеличивает при этом величину ударного объема крови, а также снижает общее периферическое сопротивление сосудов [5]. Гипертрил увеличивает продукцию NO в 
миокарде при острой ишемии и артериальной гипертензии за счет экспрессии eNOS [4]. Вышеизложенное определяет перспективность изучения Гипертрила в качестве средства комплексной терапии ХCH. В настоящее время разработана новая лекарственная форма Гипертрила - таблетки, покрытые оболочкой.

Цель исследования - на основании результатов электрокардиографии (ЭКГ) и их анализа оценить кардиопротекторную активность и особенности действия потенциального препарата «Гипертрил» при экспериментальной XCH.

Материалы и методы. Все манипуляции были проведены согласно положению об использовании животных в биомедицинских опытах [7]. Опыты выполнены на 70 белых беспородных крысах массой 190-220 г, полученных из питомников Института фармакологии и токсикологии НАМН Украины. Длительность карантина (акклиматизационного периода) для всех животных составляла 14 дней. Перед началом исследования животные, отвечающие критериям включения в эксперимент, были распределены на группы с помощью метода рандомизации. Для воспроизведения хронической сердечной недостаточности использовали доксорубициновую модель [8-10], которую можно рассматривать как наиболее эффективную, приводящую к развитию выраженной и прогрессирующей ХCH у большинства животных. Применение доксорубицина (внутрибрюшинно в кумулятивной дозе 15 мг/кг, разделенной на 6 инъекций в течение 14 дней) приводит к снижению сократимости миокарда левого желудочка, его эксцентрическому ремоделированию и формированию у крыс прогрессирующей ХCH. В исследовании использовали Доксорубицин «Ебеве»
50 мг/25 мл (ЕБЕВЕ Фарма Гесюмюб. Х. Нфг. КГ, Австрия). Гипертрил в виде таблеточной массы вводили 1 раз в сутки внутрижелудочно в дозе 3,5 мг/кг в пересчете на действующее вещество [5, 18] в виде суспезии на $1 \%$ крахмальной слизи на протяжении 30 суток после введения доксорубицина; метопролола сукцинат - по такой же схеме в дозе 15 мг/кг [10]. В этой серии эксперимента было четыре группы животных: интактные (10 крыс); контрольные - животные с $\mathrm{XCH}$ без лечения получали $1 \%$ раствор крахмальной слизи (20 крыс); животные с ХCH, получавшие таблеточную массу Гипертрил, НПО «Фарматрон» (20 крыс); животные с ХCH, получавшие Метопролола сукцинат, Astra Zeneca UK Ltd., Швеция (20 крыс). У всех групп животных на 45-е сутки эксперимента под тиопенталовым наркозом (40 мг/кг) проводили анализ ЭКГ и вегетативной регуляции сердечного ритма (ВСР), который выполняли на компьютерном анализаторе CardioCom-2000 plus (ХАИмедика, Украина).

При анализе ЭКГ параметры зубцов и интервалов рассчитывались как средняя величина модуля их амплитуды или длительности, соответственно, во всех регистрируемых отведениях.

Кроме того в течение 5 мин (не менее 1000 кардиоинтервалов) записывалась ЭКГ во 2-м стандартном отведении для изучения вегетативной регуляции сердечного ритма (BCP). Метод позволяет оценить функциональное состояние активности симпатического (адренергического) и парасимпатического (холинергического) отделов вегетативной нервной системы, их влияние на синусовый узел [11]. Определяемыми параметрами ВСР были:

1) ЧСС, мин ${ }^{-1}$;

2) величина моды (Mo, c) - продолжительность интервала RR, который 
в исследуемом отрезке электрокардиограммы встречается чаще;

3) амплитуда моды (АМо, \% ) - процент кардиоинтервалов, которые соответствуют значению моды в общей выборке;

4) вариационный размах кардиоинтервалов $(\Delta \mathrm{X}, \mathrm{c})$ - разность между наибольшим и наименьшим значениями продолжительности RR в выборке;

5) SI - индекс напряжения (индекс Баевского, стресс-индекс), который отражает напряжение регуляторных механизмов в управлении сердечным ритмом и определяется по формуле: $\mathrm{SI}=\mathrm{AMo} /(2 \cdot \Delta \mathrm{X} \cdot \mathrm{Mo})$;

6) PAPR - показатель адекватности процессов регуляции, отражает соответствие между активностью симпатического звена вегетативной нервной системы и уровнем функционирования синусового узла, определяется по формуле: PAPR = AMo/Mo;

7) $\mathrm{TPW}, \mathrm{мc}^{2}$ - суммарный уровень активности регуляторных систем, характеризует не только периодические, но и непериодические процессы; увеличение показателя рассматривают как проявление роста активности автономного контура регуляции сердечного ритма, а снижение считают признаком подавления активности автономного контура;

8) ULF, $\mathrm{Mc}^{2}$ - мощность ультра низкочастотного диапазона спектра, характеризует состояние электролитно-метаболического уровня ВCP, частично связана с процессами терморегуляции;

9) $\mathrm{VLF}, \mathrm{Mc}^{2}$ - мощность очень низкочастотного диапазона спектра, характеризует состояние энерго-метаболического уровня вегетативной регуляции сердечного ритма, под которым подразумевается выраженность эрготропных влияний надсегментарного отдела вегетативной нервной системы;
10) $\mathrm{LF}, \mathrm{Mc}^{2}$ - мощность низкочастотного диапазона спектра, является маркером симпатических влияний и/ или симпатических и парасимпатических механизмов, сопряженных с барорефлекторной регуляцией сердечного ритма; характеризует абсолютный уровень активности симпатического сосудодвигательного центра, отражает вовлеченность в регуляцию внутрисистемного уровня управления;

11) $\mathrm{HF}, \mathrm{мc}^{2}$ - мощность высокочастотного спектра, отражает периодическое усиление тонической активности блуждающего нерва (парасимпатических влияний) на сердце, синхронизированное с ритмом дыхательных движений;

12) $\mathrm{LF} / \mathrm{HF}$ - индекс вагосимпатического взаимодействия, характеризует относительное преобладание активности подкоркового симпатического нервного центра над активностью парасимпатического канала регуляции сердечного ритма;

13) IC - индекс централизации, характеризует относительное преобладание центрального контура регуляции над автономным контуром, отражает степень централизации управления сердечным ритмом, определяется по формуле: $\mathrm{IC}=(\mathrm{LF}+\mathrm{VLF}) / \mathrm{HF}$.

Для анализа ВСР с помощью системы Cardiolab использовали программный пакет с функцией распознавания ритма с высокой ЧСС (до 500 уд. в мин) специально для регистрации ЭКГ у мелких грызунов.

Результаты исследования обработаны с применением статистического пакета лицензионной программы «STATISTICA ${ }^{\circledR}$ for Windows 6.0» (StatSoftInc., № AXXR712D833214FAN5), а также «SPSS 16.0», «Microsoft Excel 2003». Отдельные статистические процедуры и алгоритмы реализованы в виде специально написанных макросов в соответствующих программах. Для всех 
видов анализа статистически значимыми считали различия при р $<0,05$ по критерию Стьюдента.

Результаты и их обсуждение. Сравнительный анализ состояния функции электрической активности сердца показывает, что у животных интактной и всех экспериментальных групп наблюдался правильный ритм сердца с преобладанием зубца $\mathrm{R}$ во всех стандартных отведениях, с преобладанием его амплитуды во 2-м стандартном отведении. ЧСС в состоянии легкого наркоза у отдельных животных составляла от 280 до 420 уд./мин, что соответствует нормальной деятельности сердечной мышцы у крыс в покое в условиях свободного поведения. То есть, действие легкого наркоза не сказывалось на функции сердца.

Моделирование ХCH 14-суточным введением доксорубицина приводило на 35-е сутки эксперимента к увеличению ЧСС на 50 \%, что приводило к укорочению длительности сердечного цикла RR на 33,5 \% (табл. 1).

ЭКГ животных с XCH характеризовалась элевацией сегмента ST над изолинией примерно на 0,1 мB (в 14,3 раза). Сократительная функция желудочков характеризовалась увеличением на $36 \%$ амплитуды зубца $\mathrm{R}$ в сочетании с удлинением фазы их деполяризации (комплекс QRS) на 11,5\% и реполяризации (зубец $\mathrm{T}$ ) на $9,5 \%$ относительно длительности сердечного

Таблица 1

Показатели электрокардиографии в условиях моделирования у крыс хронической сердечной недостаточности и применения Гипертрила $(M \pm m)$

\begin{tabular}{|c|c|c|c|c|}
\hline \multirow[b]{2}{*}{$\begin{array}{c}\text { Пока- } \\
\text { затель } \\
\text { ЭКГ }\end{array}$} & \multicolumn{4}{|c|}{ Экспериментальная группа } \\
\hline & $\begin{array}{l}\text { интактные } \\
\text { животные }\end{array}$ & $\begin{array}{c}\text { хроническая } \\
\text { сердечная } \\
\text { недостаточность } \\
\text { (контроль) }\end{array}$ & $\begin{array}{c}\text { хроническая } \\
\text { сердечная } \\
\text { недостаточность } \\
\text { + Метопролол, } \\
15 \text { мг/кг }\end{array}$ & $\begin{array}{c}\text { хроническая } \\
\text { сердечная } \\
\text { недостаточность } \\
\text { + Гипертрил, } \\
\text { 3,5 мг/кг }\end{array}$ \\
\hline ЧСС, мин $^{-1}$ & $354,4 \pm 20,9$ & $532,6 \pm 18,1^{1,3,4}$ & $422,6 \pm 23,4^{1,2}$ & $388,7 \pm 16,9^{2}$ \\
\hline \multicolumn{5}{|c|}{ Амплитуда зубцов, мВ } \\
\hline$P$ & $0,021 \pm 0,003$ & $0,019 \pm 0,003$ & $0,029 \pm 0,005$ & $0,018 \pm 0,001$ \\
\hline$R$ & $0,160 \pm 0,013$ & $0,218 \pm 0,016^{1}$ & $0,215 \pm 0,017^{1}$ & $0,182 \pm 0,014$ \\
\hline$T$ & $0,081 \pm 0,010$ & $0,047 \pm 0,006^{1}$ & $0,080 \pm 0,009^{2}$ & $0,092 \pm 0,012^{2}$ \\
\hline ST & $-0,006 \pm 0,009$ & $0,092 \pm 0,027^{1,4}$ & $0,048 \pm 0,01^{1,4}$ & $0,020 \pm 0,004^{1,2,3}$ \\
\hline \multicolumn{5}{|c|}{ Длительность интервалов, мс } \\
\hline$P Q$ & $41,0 \pm 2,5$ & $32,0 \pm 1,6^{1,4}$ & $30,8 \pm 1,9^{1,4}$ & $26,9 \pm 0,5^{1,2,3}$ \\
\hline QRS & $31,0 \pm 0,8$ & $33,6 \pm 1,4^{4}$ & $31,2 \pm 0,3^{4}$ & $29,4 \pm 0,4^{2,3}$ \\
\hline$T$ & $48,6 \pm 2,4$ & $42,8 \pm 2,3^{3}$ & $71,2 \pm 7,6^{1,2,4}$ & $52,8 \pm 1,4^{2,3}$ \\
\hline TP & $48,6 \pm 2,4$ & $4,2 \pm 0,2^{1,3,4}$ & $8,7 \pm 0,4^{1,2,4}$ & $45,1 \pm 2,2^{2,3}$ \\
\hline RR & $169,2 \pm 5,0$ & $112,6 \pm 3,3^{1,3,4}$ & $141,9 \pm 4,2^{1,2}$ & $154,3 \pm 4,6^{1,2}$ \\
\hline \multicolumn{5}{|c|}{ Длительность интервалов, процент к длительности сердечного цикла RR } \\
\hline$P Q$ & $24,2 \pm 1,4$ & $28,4 \pm 1,5^{1,3,4}$ & $21,6 \pm 1,3^{2,4}$ & $17,4 \pm 0,3^{1,2,3}$ \\
\hline QRS & $18,3 \pm 0,5$ & $29,8 \pm 1,2^{1,3,4}$ & $21,9 \pm 0,2^{1,2,4}$ & $19,0 \pm 0,2^{2,3}$ \\
\hline $\mathrm{T}$ & $28,7 \pm 1,4$ & $37,9 \pm 2,0^{1,3}$ & $50,1 \pm 5,3^{1,2,4}$ & $34,2 \pm 0,9^{1,3}$ \\
\hline TP & $28,7 \pm 1,4$ & $3,7 \pm 0,1^{1,3,4}$ & $6,1 \pm 0,3^{1,2,4}$ & $29,2 \pm 1,4^{2,3}$ \\
\hline
\end{tabular}

Прилечание. Здесь и в табл. 2: ${ }^{1}$ достоверность изленений $P_{S T}<0,05$ по отношению $\kappa$ интактныл животныл, ${ }^{2}-\kappa$ животныл с ХСН, ${ }^{3}-$ при лечении летопрололол, ${ }^{4}-$ при лечении гипертрилол. 
цикла, снижением спектральной мощности сердечного ритма TPW и увеличением стресс-индекса SI в 2,7 раза. При этом в спектральной характеристике работы сердца увеличивалась мощность высокочастотного компонента, который связан с активацией парасимпатических влияний на сердце и снижением индекса вагосимпатического взаимодействия $\mathrm{LF} / \mathrm{HF}$ в 5 раз (табл. 2).

Полученные данные свидетельствуют о компенсаторной активации парасимпатической регуляции сердечного цикла со стороны блуждающего нерва в ответ на тахикардию. Однако данную компенсацию следует расценивать как неэффективную, о чем свидетельствовало существенное ослабление центрального контура регуляции сердечного ритма над автономным контуром (снижение индекса централизации IC в 13 раз) и преобладание симпатического контура вегетативной регуляции в механизмах нейрогенного контроля функции синусового узла (увеличение показателя адекватности процессов регуляции сердечного ритма PAPR на 50 \% ). Несмотря на снижение длитель- ности интервала $\mathrm{PQ}$ при XCH, его длительность относительно протяженности сердечного цикла $\mathrm{RR}$ достоверно увеличивалась на $4,2 \%$, что свидетельствовало об относительном замедлении атриовентрикулярной проводимости. В сочетании с уширением длительности желудочкового комплекса QRS на 11,5 \% это указывало, что наряду с нарушением электрических процессов де- и реполяризации развитие ХCH у экспериментальных животных сопровождалось нарушением процессов проводимости, что, очевидно, связано с нарушением метаболизма миокарда и его проводящей системы при экспериментальной патологии. Результатом выявленных нарушений в работе сердца при ХCH было также существенное ограничение времени электрической диастолы, которая сокращалась с $(48,6 \pm 2,4)$ мс у интактных крыс до $(4,2 \pm 0,2)$ мс (в 11,6 раза) у крыс с экспериментальной патологией. Учитывая то обстоятельство, что физиологическая диастола необходима не только для адекватной внутрисердечной гемодинамики, но и для ресинтеза пула макроэргических молекул в

Таблица 2

Характеристики вегетативной регуляции сердечного ритла у крыс в условиях моделирования хронической сердечной недостаточности и применения Гипертрила $(M \pm m)$

\begin{tabular}{|c|c|c|c|c|}
\hline \multirow[b]{2}{*}{$\begin{array}{c}\text { Показа- } \\
\text { тель веге- } \\
\text { тативной } \\
\text { регуляции } \\
\text { сердечно- } \\
\text { го ритма }\end{array}$} & \multicolumn{4}{|c|}{ Экспериментальная группа } \\
\hline & $\begin{array}{l}\text { интактные } \\
\text { животные }\end{array}$ & $\begin{array}{c}\text { хроническая } \\
\text { сердечная } \\
\text { недостаточ- } \\
\text { ность } \\
\text { (контроль) }\end{array}$ & $\begin{array}{c}\text { хроническая } \\
\text { сердечная недо- } \\
\text { статочность } \\
\text { + Метопролол, } \\
15 \text { мг/кг }\end{array}$ & $\begin{array}{c}\text { хроническая } \\
\text { сердечная недо- } \\
\text { статочность } \\
\text { + Гипертрил, } \\
\text { 3,5 мг/кг }\end{array}$ \\
\hline TPW, $\mathrm{Mc}^{2}$ & $8,316 \pm 1,728$ & $2,460 \pm 0,50^{1,4}$ & $3,040 \pm 0,177^{1,4}$ & $4,550 \pm 0,193^{2,3}$ \\
\hline ULF, $\mathrm{MC}^{2}$ & $5,633 \pm 1,355$ & $0,408 \pm 0,198^{4}$ & $0,920 \pm 0,073^{4}$ & $2,860 \pm 0,050^{2,3}$ \\
\hline VLF, $\mathrm{MC}^{2}$ & $2,30 \pm 0,410$ & $0,820 \pm 0,452^{1}$ & $1,580 \pm 0,120$ & $1,420 \pm 0,131$ \\
\hline $\mathrm{LF}, \mathrm{Mc}^{2}$ & $0,250 \pm 0,034$ & $0,320 \pm 0,295$ & $0,260 \pm 0,060$ & $0,160 \pm 0,080$ \\
\hline $\mathrm{HF}, \mathrm{Mc}^{2}$ & $0,133 \pm 0,021$ & $0,804 \pm 0,815$ & $0,208 \pm 0,080$ & $0,110 \pm 0,010$ \\
\hline $\mathrm{LF} / \mathrm{HF}$ & $1,875 \pm 0,381$ & $0,380 \pm 0,372^{1,3,4}$ & $0,928 \pm 0,562^{1,2,4}$ & $1,454 \pm 0,484^{2,3}$ \\
\hline IC & $19,125 \pm 0,807$ & $1,357 \pm 0,255^{1,3,4}$ & $6,571 \pm 1,010^{1,2,4}$ & $14,363 \pm 1,310^{1,2,3}$ \\
\hline SI & $12768 \pm 1375$ & $34587 \pm 1469^{1,3,4}$ & $28378 \pm 1356^{1,2,4}$ & $23050 \pm 1471^{1,2,3}$ \\
\hline PAPR & $476,1 \pm 46,1$ & $518,8 \pm 140,7$ & $607,6 \pm 134,1$ & $835,4 \pm 99,21$ \\
\hline
\end{tabular}


миокардиоцитах, ее укорочение очевидно усугубляет энергетический дефицит сердца и ухудшает его работу. По всей видимости, данная модель ХСН приводит к формированию стойкой диастолической дисфункции.

Таким образом, комплекс выявленных изменений демонстрирует нарушение электрической работы сердца (по данным ЭКГ - нарушение автоматизма, проводимости и сократимости) и нейрогенных механизмов ее регуляции (по данным ВСР - децентрализация нейрогенных контуров регуляции, снижение мощности спектра и увеличение стресс-индекса), что может в данном случае рассматриваться как проявление диастолической дисфункции у животных с экспериментальной ХСН. Введение метопролола животным с ХCH достоверно снижало у них ЧСС, однако данный показатель был на $19 \%$ выше, чем у животных в интактной группе. В группе, получавшей метопролол, наблюдалось достоверное снижение уровня элевации сегмента ST (практически в 2 раза по сравнению с животными без лечения), что свидетельствует об противоишемическом действии препарата, а также нормализация амплитуды зубца реполяризации желудочков Т.

Длительность реполяризации (зубец Т) в группе метопролола более чем на 40 \% превышала аналогичный показатель у интактных крыс и нелеченных животных с ХCH, и составляла 50 \% от длительности сердечного цикла RR. Длительность электрической диастолы ТP в группе, получавшей метопролол, хотя и увеличивалась в 2 раза по сравнению с животными с ХCH, но оставалась при этом в 5 раз короче, чем у интактных животных.

Полученные данные свидетельствовали о том, что метопролол не вызывал эффективного увеличения электрической диастолы, и, следователь- но, существенно не влиял на диастолическую дисфункцию сердца. Вместе с тем, введение метопролола животным с $\mathrm{XCH}$ достоверно увеличивало спектральную мощность сердечного ритма TPW (на $28 \%$ ) и снижало стресс-индекс SI (на $18 \%$ ), достоверно повышало индекс централизации IC (в 4,8 раза) и индекс вагосимпатического взаимодействия $\mathrm{LF} / \mathrm{HF}$ в 2,4 раза. То есть, результаты ЭКГ после введения метопролола животным с $\mathrm{XCH}$ свидетельствовали о некоторой сбалансированности нейрогенных механизмов регуляции сердечного ритма и повышении роли центральных контуров симпатического контроля работы сердца. Введение Гипертрила животным с ХCH оказывало выраженный отрицательный хронотропный эффект и практически нормализовало ЧСС у крыс с ХCH. На ЭКГ отмечалась нормализация амплитуды желудочкового зубца $\mathrm{R}$ и нормализация амплитуды зубца реполяризации Т, что, очевидно, могло быть связано с улучшением энергетического обеспечения миокарда и более рациональным использованием макроэргов для обеспечения сократительной функции сердца. Косвенным подтверждением данного предположения, а также наличия выраженного противоишемического эффекта у Гипертрила является существенное снижение амплитуды сегмента ST над изолинией - в 4 раза по сравнению с показателем животных с ХСН без лечения и в 2,5 раза по сравнению с животными с ХCH, получавшими курсом метопролол. Значительным с точки зрения терапии ХCH эффектом Гипертрила следует считать нормализацию (приведение до значения интактных животных) длительности фазы деполяризации (комплекс QRS) и реполяризации желудочков (зубец Т), а также электрической диастолы (интервал ТP). 
Это свидетельствует о том, что применение Гипертрила предотвращает формирование диастолической дисфункции. В современной медицинской литературе имеются сведения о том, что признаки диастолической дисфункции миокарда выявляются практически при любом заболевании сердца, но особенно у пациентов с XCH [12].

Наряду с этим установлена взаимосвязь между степенью нарушения диастолической функции сердца и тяжестью $\mathrm{XCH}$, а также толерантностью к физическим нагрузкам и качеством жизни. Диастолическая дисфункция у больных ХCH является прогностически значимым фактором. Прогрессирование диастолической дисфункции приводит $\kappa$ развитию еще более тяжелой формы $\mathrm{XCH,} \mathrm{называемой} \mathrm{рестрик-}$ тивной, которая имеет наихудший прогноз и является важнейшим предиктором сердечно-сосудистой смертности $[13,14]$. Доказательная база применения лекарственных препаратов (ингибиторы АПФ, $\beta$-адреноблокаторы, блокаторы кальциевых каналов) в лечении ХCH с диастолической дисфункцией небольшая, что требует создания новых эффективных средств [15-17]. Следует отметить, что введение Гипертрила оказывало некоторое ускорение атриовентрикулярной проводимости - сокращение интервала $\mathrm{PQ}$, достоверное даже по отношению к группе контрольных животных. Введение Гипертрила животным с $\mathrm{XCH}$ значительно повышало спектральную мощность сердечного ритма TPW (на $85 \%$ ) и увеличивало показатель адекватности процессов регуляции сердечного ритма PAPR. У экспериментальных животных, получавших Гипертрил, снижался стресс-индекс SI (на $33 \%$ ), достоверно повышался индекс централизации IC (в 10 раз) и нормализовался индекс вагосимпатического взаимодействия LF/HF.
Введение Гипертрила животным с $\mathrm{XCH}$ свидетельствовало о существенном восстановлении нейрогенных механизмов регуляции сердечного ритма и сбалансированности активности симпатического и парасимпатического звеньев вегетативной нервной системы в контроле работы сердца. Механизм подобного влияния Гипертрила на показатели ЭКГ у крыс с ХCH, по всей видимости, связан не только с его $\beta_{1}$-адреноблокирующим действием, но и, возможно, реализуется за счет дополнительных механизмов, выявленных на моделях экспериментального инфаркта миокарда и артериальной гипертензии - антиоксидатного, противоишемического, а также за счет влияния на систему NO миокарда [4-6, 18].

Таким образом, курсовое введение таблеток «Гипертрил» крысам с ХCH в дозе 3,5 мг/кг приводит к улучшению показателей ЭКГ, характерному для кардиоселективных $\beta$-адреноблокаторов с вазодилатирующим эффектом - улучшает показатели ЭКГ приводит значения ЧСС до уровня здоровых животных, снижает суммарную степень отклонения интервала $\mathrm{ST}(\Sigma \Delta \mathrm{ST})$ от изолинии в 4 раза, что в сочетании с восстановлением амплитуды зубца $\mathrm{R}$ и зубца реполяризации $\mathrm{T}$ указывает на сохранение более высокой работоспособности миокардиоцитов и проявление противоишемического действия у исследуемого препарата.

Выявленная на ЭКГ нормализация амплитуды желудочкового зубца $\mathrm{R}$ и нормализация амплитуды зубца реполяризации Т под действием Гипертрила связана с улучшением энергетического обеспечения миокарда и более рациональным использованием макроэргов для обеспечения сократительной функции сердца. 
Применение Гипертрила у животных с ХCH приводит до значения здоровых животных длительность фазы деполяризации (комплекс QRS) и реполяризации желудочков (зубец Т), a также электрической диастолы (интервал ТР), что свидетельствует о важном свойстве препарата с точки зрения терапии ХCH - способности предотвращать формирование диастолической дисфункции. Это ключевой аспект в кардиопротективном действии Гипертрила, так как прогрессирование диастолической дисфункции приводит к развитию еще более тяжелой формы ХCH, называемой рестриктивной, которая имеет наихудший прогноз и является важнейшим предиктором сердечно-сосудистой смертности. Гипертрил повышает спектральную мощность сердечного ритма TPW, увеличивает показатель адекватности процессов регуляции сердечного ритма PAPR и снижает стрессиндекс SI на фоне повышения индекса централизации IC и нормализует индекс вагосимпатического взаимодействия LF/HF. Все это свидетельствует о восстановлении нейрогенных механизмов регуляции сердечного ритма и сбалансированности активности симпатического и парасимпатического звеньев вегетативной нервной системы в контроле работы сердца при ХCH. По степени влияния на некоторые показатели ЭКГ Гипертрил достоверно превосходит Метопрола сукцинат (15 мг/кг). Полученные результаты являются экспериментальным обоснованием перспективно- сти дальнейшего исследования потенциального препарата Гипертрил в виде таблеток.

\section{Выводы}

1. Курсовое внутрижелудочное введение Гипертрила (3,5 мг/кг) крысам c ХCH приводит к улучшению показателей ЭКГ - нормализации ЧСС, комплекса QRS, зубца T, интервала TP, уменьшению в 4 раза отклонения интервала $\Sigma \Delta \mathrm{ST}$ от изолинии, восстановлению амплитуды зубца $\mathrm{R}$ и зубца реполяризации Т.

2. Гипертрил повышает спектральную мощность сердечного ритма TPW, увеличивает показатель адекватности процессов регуляции сердечного ритма PAPR, снижает стресс-индекс SI на фоне повышения индекса централизации IC и нормализует индекс вагосимпатического взаимодействия LF/HF у крыс с ХCH.

3. По всей видимости, кардиопротективное действие Гипертрила направлено на улучшение сократительной функции миокарда, предотвращение формирования диастолической дисфункции, восстановление нейрогенных механизмов регуляции сердечного ритма и сбалансированности активности симпатического и парасимпатического звеньев вегетативной нервной системы в контроле работы сердца при ХCH.

4. По степени влияния на некоторые показатели ЭКГ Гипертрил (3,5 мг/ кг) достоверно превосходит Метопролола сукцинат (15 мг/кг).

1. Statistics of heart failure and mechanical circulatory support in 2020. R. E. S. Bowen, T. J. Graetz, D. A. Emmert et al. Ann Transl Med. 2020. V. 8 (13). P. 827. https://doi.org/10.21037/atm-20-1127.

2. The global health and economic burden of hospitalizations for heart failure: lessons learned from hospitalized heart failure registries. A. P. Ambrosy, G. C. Fonarow, J. Butleret al. J Am CollCardiol. 2014. V. 63. P. 1123-1133. https://doi.org/10.1016/j.jacc.2013.11.053.

3. Воронков Л. Г. Хронічна серцева недостатність у хворих похилого віку: особливості патогенезу, діагностики та фармакотерапії. Серце і судини. 2005. № 2. С. 89-96.

4. Чекман И. С., Беленичев И. Ф., Мазур И. А. NO-зависимые механизмы кардиопротекторного действия препарата MT при курсовом назначении SHR-крысам. Экспериментальная и клиническая фармакология. 2013. Т. 76, № 8. С. 24-26. 
5. Патент на изобретение РФ № 2404974. Мазур И. А., Беленичев И. Ф., Колесник Ю. М. заявл. 10.12.2008.

6. Antihypertensive and cardioprotective effects of new compound 1-( $\beta$-phenylethyl)-4-amino-1,2,4triazolium bromide (Hypertril). I. Belenichev, I. Mazur, L. Kucherenko et al. European Journal of Pharmacology. 2019. V. 853. P. 336-344.

7. Чадаев В. Е. Этические принципы при работе с лабораторными животными. Вісник проблем біології і медицини. 2012. № 2.

8. Identification of the molecular basis of doxorubicin-induced cardiotoxicity. S. Zhang, X. Liu, T. BawaKhalfe et al. Nat Med. 2012. V. 18. P. 1639-1642.

9. Use of speckle strain to assess left ventricular responses to cardiotoxic chemotherapy and cardioprotection. K. Negishi, T. Negishi, B. A. Haluska et al. Eur Heart J Cardiovasc Imaging. 2014. V. 15. P. 324-331.

10. Хлопонин Д. П. Анализ возможных механизмов фармакологической реверсии кардиального ремоделирования при хронической сердечной недостаточности: дис. д-ра мед. наук. Волгоград, 2009. 320 c.

11. Bigger J. T. Spectral analysis of R-R variability to evaluate autonomic physiology and pharmacology and to predict cardiovascular outcomes in humans. Zipes D. P. (Eds.). Cardiac electrophysiology: from cell to bedside. Philadelphia, PA : WB Saunders Co, 1995. P. 1151-1170.

12. Ageev F. T. Modern concept of diastolic heart failure. Cardiovascular Therapy and Prevention 2021. V. 9 (7). P. $97-104$.

13. Doxorubicin-induced and trastuzumab-induced cardiotoxicity in mice is not prevented by metoprolol M. Nicol, M. Sadoune, E. Polidano, J. M. Launay. ESC Heart Failure. 2021. V. 21. P. 12-27.

14. Чекман И. С., Беленичев И. Ф., Кучеренко Л. И. Доклиническое изучение специфической активности эндотелиопротективных препаратов. Методические рекомендации. Киев : ГЭЦ МЗ Украины, 2014. 60 с.

15. Bidirectional cross-regulation between ErbB2 and $\beta$-adrenergic signalling pathways. P. Sysa-Shah, C. G. Tocchetti, M. Gupta et al. Cardiovasc Res. 2016. V. 109. P. 358-373.

16. Coronary endothelial dysfunction increases the severity of ischaemia-induced ventricular arrhythmias in rat isolated perfused hearts. Z. F. Hassanabad, B. L. Furman, J. R. Parratt et al. Basic. Res. Cardiol. 2008. V. 93. № 4. P. 241-249.

17. Визир В. А. Перспективы реверсии эндотелиальной дисфункции у больных застойной сердечной недостаточностью. Клиническая медицина. 2000. № 7. С. 36-39.

18. Бак П. Г., Бєленічев І. Ф., Бухтіярова Н. В. Функціональна активність мітохондрій міокарда щурів з експериментальною XCH на тлі курсового введення $\beta$-адреноблокатора з NO-модулюючим ефектом «Гіпертріл». Актуальні питання сучасної медицини і фармації: зб. тез доп. наук.-практ. конф. з міжнар. участю молодих вчених та студентів, 13-17 травня 2019 р. Запоріжжя : ЗДМУ, 2019. С. 137.

\section{И. Ф. Беленичев, П. Г. Бак, А. В. Абрамов, Л. И. Кучеренко,}

\section{Н. В. Бухтиярова, В. П. Рыженко}

\section{Анализ ЭКГ при моделировании хронической сердечной недостаточности} у крыс и курсовом введении нового потенциального препарата «Гипертрил"

Цель исследования - на основании результатов электрокардиографии (ЭКГ) и их анализа оценить кардиопротекторную активность и особенности действия потенциального препарата «Гипертрил» при экспериментальной хронической сердечной недостаточности (XCH).

Экспериментальная часть работы выполнена на 70 белых беспородных крысах массой 190 - 220 г. ХCH моделировали введением доксорубицина (внутрибрюшинно в кумулятивной дозе 15 мг/кг, разделенной на 6 инъекций в течение 14 дней). Исследуемые препараты - Гипертрил вводили 1 раз в сутки внутрижелудочно в дозе 3,5 мг/кг на протяжении 30 суток; метопролола сукцинат - по такой же схеме в дозе 15 мг/кг. Наличие XСН подтверждали методом ЭКГ при помощи компьютерного анализатора Cardio Com-2000 plus (ХАИ-медика, Украина).

Моделирование XCH у экспериментальных животных приводило к элевации сегмента ST над изолинией примерно на 0,1 мB (в 14,3 раза), к увеличению сократительной функции желудочков (увеличение амплитуды зубца R на 36 \%) в сочетании с удлинением фазы их деполяризации (комплекс QRS) на 11,5 \% и реполяризации (зубец T) на 9,5 \% относительно длительности сердечного цикла, снижением спектральной мощности сердечного ритма TPW и увеличением стресс-индекса SI в 2,7 раза, к сокращению времени электрической диастолы до (4,2 \pm 0,2) мс (в 11,6 раза). На фоне введения метопролола длительность реполяризации более чем на 40 \% превышала аналогичный показатель у интактных крыс и нелеченных животных с ХCH, и составляла 50 \% от длительности сердечного цикла RR. Длительность электрической диастолы TP хотя и увеличивалась в 2 раза по сравнению с животными с XCH, но оставалась при этом в 5 раз короче, чем у интактных животных. На фоне введения Гипертрила на ЭКГ отмечалась нормализация амплитуды желудочкового зубца $\mathrm{R}$ и нормализация амплитуды зубца реполяризации Т, существенное снижение амплитуды сегмен- 
та ST над изолинией - в 4 раза по сравнению с контрольной группой и в 2,5 раза по сравнению с животными, получавшими курсом метопролол, нормализация длительности комплекса QRS и зубца Т, а также интервала ТР. Это свидетельствует о том, что курсовое применение Гипертрила предотвращает формирование диастолической дисфункции.

Полученные результаты являются экспериментальным обоснованиям перспективности дальнейшего исследования потенциального препарата «Гипертрил» в виде таблеток.

Ключевые слова: хроническая сердечная недостаточность, Гипертрил, 4-амино1,2,4-триазолы, $\beta$-адреноблокатор, метопролол, кардиопротекция

\section{І. Ф. Бєленічев, П. Г. Бак, А. В. Абрамов, Л. І. Кучеренко, \\ Н. В. Бухтіярова, В. П. Риженко \\ Аналіз ЕКГ за моделювання хронічної серцевої недостатності в щурів і курсового введення нового потенційного препарату “Гіпертрил"}

Мета дослідження - за результатами електрокардіографії (ЕКГ) та їх аналізу оцінити кардіопротективну активність та особливості дії потенційного препарата «Гіпертрил» на моделі хронічної серцевої недостатності (XCH).

Експериментальну частину дослідження виконано на 70 білих безпородних щурах масою 190220 г. ХСН моделювали введенням доксорубіцину (внутрішньоочеревинно в кумулятивній дозі 15 мг/ кг, розділеній на 6 ін'єкцій протягом 14 днів). Досліджувані препарати - Гіпертрил вводили 1 раз на добу внутрішньошлунково в дозі 3,5 мг/кг протягом 30 діб; метопрололу сукцинат - за такою самою схемою в дозі 15 мг/кг. Наявність ХСН підтверджували методом ЕКГ за допомогою комп'ютерного аналізатора CardioCom-2000 plus (XAІ-медика, Україна).

Моделювання XCH у експериментальних тварин призводило до підйому сегмента ST над ізолінією приблизно на 0,1 мB (у 14,3 разу), збільшення скорочувальної функції шлуночків (збільшення на 36 \% амплітуди зубця R) у поєднанні з подовженням фази їхньої деполяризації (комплекс QRS) на 11,5 \% і реполяризації (зубець Т) на 9,5 \% щодо тривалості серцевого циклу, зниження спектральної потужності серцевого ритму TPW і збільшення стрес-індексу SI у 2,7 разу, до скорочення часу електричної діастоли до $(4,2 \pm 0,2)$ мс (у 11,6 разу). На фоні введення метопрололу тривалість реполяризації більше ніж на 40 \% перевищувала аналогічний показник в інтактних щурів і нелікованих тварин з XCH, і становила 50 \% від тривалості серцевого циклу RR. Тривалість електричної діастоли ТР хоча й збільшувалася в 2 рази порівняно з тваринами з ХCH, але залишалася при цьому в 5 разів коротшою, ніж в інтактних тварин. На фоні введення Гіпертрилу на ЕКГ відзначалася нормалізація амплітуди шлуночкового зубця R і нормалізація амплітуди зубця реполяризації Т, суттєве зниження амплітуди сегмента ST над ізолінією - у 4 рази порівняно з контрольною групою й у 2,5 разу порівняно з тваринами, які отримували курсом метопролол, нормалізація тривалості комплексу QRS i зубця Т, а також інтервалу ТР.

Це свідчить про те, що курсове застосування Гіпертрилу запобігає формуванню діастолічної дисфункції. Отримані результати є експериментальним обґрунтуванням перспективності подальшого дослідження потенційного препарату «Гіпертрил» у вигляді таблеток.

Ключові слова: хронічна серцева недостатність, Гіпертрил, 4-аміно- 1,2,4-триазоли, $\beta$-адреноблокатор, метопролол, кардіопротекція

\section{F. Belenichev, P. G. Bak, A. V. Abramov, L. I. Kucherenko, N. V. Bukhtiyarova, V. P. Ryzhenko$$
\text { ECG analysis under chronic heart failure modeling in rats and course }
$$ administration of a new potential drug "Hypertril»}

The aim of the study - based on research of electrocardiography to evaluate cardioprotective effect and features of action of new potential drug «Hypertril» under chronic heart failure (CHF) modeling.

The experimental part of the work was performed on 70 outbred white rats weighing 190-220 g. Chronic heart failure was modeled by the administration of doxorubicin (intraperitoneally at a cumulative dose of $15 \mathrm{mg} / \mathrm{kg}$, divided into 6 injections over 14 days). Study drugs - Hypertril was administered once a day intragastrically at a dose of $3,5 \mathrm{mg} / \mathrm{kg}$ for 45 days; metoprolol succinate - according to the same scheme at a dose of $15 \mathrm{mg} / \mathrm{kg}$. The presence of CHF was confirmed by electrocardiography using a CardioCom-2000 plus computer analyzer (XAI-medika, Ukraine).

Modeling CHF in experimental animals led to elevation of the ST segment above the isoline by about 0,1 $\mathrm{mV}$ (14,3 times), to an increase in the contractile function of the ventricles (increase by $36 \%$ of the amplitude of the $\mathrm{R}$ wave) in combination with an extension of the phase of their depolarization (QRS complex) by $11,5 \%$ and repolarization ( $T$ wave) by $9,5 \%$ relative to the duration of the cardiac cycle, a decrease in the spectral power of the heart rate TPW and an increase in the stress index SI by 2,7 times, to a decrease in the time of electric diastole to $(4,2 \pm 0,2) \mathrm{ms}(11,6$ times). After metoprolol administration the duration of repolarization was more than $40 \%$ higher than that in intact rats and untreated animals with $\mathrm{CHF}$, and it was $50 \%$ of the RR cardiac cycle duration. The duration of electrical diastole TR, although it 
increased 2 times compared with animals with CHF, but it remained 5 times shorter than in intact animals. After Hypertril administration the ECG showed normalization of the amplitude of the ventricular R wave and normalization of the amplitude of the $T$ repolarization wave, a significant decrease in the amplitude of the ST segment above the isoline - 4 times compared with the control group and 2,5 times compared with animals treated with metoprolol, normalization of the duration of the QRS complex and the T wave, as well as the TR interval. This indicates that course administration of Hypertril prevents the formation of diastolic dysfunction.

The result obtained are experimental substantiation of the prospects for further research of the potential drug Hypertril in the form of tablets.

Key words: chronic heart failure, Hypertril, endothelial dysfunction, $\beta$-blocker, metoprolol, cardioprotection

Надійшла: 13 січня 2021 р.

Прийнята до друку: 23 лютого 2021 р.

Контактна особа: Бєленічев І. Ф., кафедра фармакології та медичної рецептури з курсом нормальної фізіології, Запорізький державний медичний університет, буд. 31, вул. Сталеварів, м. Запоріжжя, 69035. Тел.: + 380612342741. 